\title{
Pengaruh Good Corporate Governance Terhadap Kualitas Laba Pada Perusahaan Real Estate dan Property
}

\section{The Effect of Good Corporate Governance Towards Quality of Profit At Real Estate And Property Company.}

\author{
Vika Fitranita $\left.{ }^{1}\right)$, Isma Coryanata $\left.{ }^{2}\right)$ \\ Fakultas Ekonomi dan Bisnis Universitas Bengkulu \\ fitranitavika@gmail.com ${ }^{1)}$, ismacoryanata@yahoo.com ${ }^{2)}$
}

\begin{abstract}
This study aims to analyze the effect of corporate governance on the quality of study earnings in real estate and property companies listed on the Indonesia Stock Exchange (IDX) in 2012-2017. In this study, Good Corporate Governance is analyzed as a factor that can encourage companies to have good earnings quality. This study belongs to the type of descriptive research verification of causality. The population in this study are real estate and property companies listed on the Indonesia Stock Exchange (IDX) in 2012-2017 using the purposive sampling method. The type of data collected and used in this study is secondary data with a method of collecting data through documentation and literature studies. The data analysis method used is simple linear regression analysis that has met the testing of classical assumptions. The results of this study indicate that Good Corporate Governance has no effect on earnings quality because the application of Good Corporate Governance (GCG) in companies in Indonesia has not really been used as a tool to minimize information asymmetry between owners and management, but solely to comply with regulations and conditions that apply only.
\end{abstract}

Key words: Good Coporate Governance, kualitas laba.

\begin{abstract}
ABSTRAK
Penelitian ini bertujuan untuk menganalisis pengaruh corporate governance terhadap kualitas laba studi pada perusahaan real estate dan property yang terdaftar di Bursa Efek Indonesia (BEI) tahun 2012-2017. Pada penelitian ini, Good Corporate Governance yang dianalisis sebagai faktor yang dapat mendorong perusahaan untuk mempunyai kualitas laba yang baik. Penelitian ini termasuk ke dalam jenis penelitian deskrtiptif verifikatif bersifat kausalitas. Populasi pada penelitian ini adalah perusahaan real estate dan property yang terdaftar di Bursa Efek Indonesia (BEI) tahun 2012-2017 dengan menggunakan metode purposive sampling. Jenis data yang dikumpulkan dan digunakan dalam penelitian ini adalah data sekunder dengan metode pengumpulan data melalui studi dokumentasi dan studi pustaka. Metode analisis data yang digunakan adalah analisis regresi linear sederhana yang telah memenuhi pengujian asumsi klasik. Hasil penelitian ini menunjukkan Good Corporate Governance tidak berpengaruh terhadap kualitas laba karena penerapan Good Corporate Governance (GCG) pada perusahaan-perusahaan di Indonesia belum benar-benar digunakan sebagai alat untuk meminimalkan asimetri informasi antara pemilik dan manajemen, namun semata-mata hanya untuk memenuhi peraturan dan ketentuan yang berlaku saja.
\end{abstract}

Kata Kunci: Good Coporate Governance, kualitas laba.

\section{PENDAHULUAN}

Terjadinya agency conflict disebabkan pihak-pihak terkait yaitu principal dan agent yang mempunyai kepentingan yang saling bertentangan. Jika agent dan principal berupaya memaksimalkan utilitas masing-masing, serta memiliki keinginan dan motivasi yang berbeda, maka ada alasan untuk percaya bahwa agen (manajemen) tidak selalu bertindak sesuai dengan keinginan principal (Triatmoko, 2007) 
Manajer sebagai pengelola lebih banyak mengetahui informasi internal dan prospek perusahaan di masa yang akan datang dibandingkan dengan principal. Principal tidak memiliki informasi yang cukup tentang kinerja agent. Hal ini yang mengakibatkan adanya ketidakseimbangan informasi yang dimiliki oleh principal dan agent. Ketidakseimbangan informasi ini yang disebut dengan asimetri informasi. Asimetri informasi dan konflik kepentingan yang terjadi antara principal dan agent dapat mendorong agent untuk menyajikan informasi yang tidak sebenarnya kepada principal, terutama jika informasi tersebut berkaitan dengan pengukuran kinerja agent (Utari, 2006)

Konflik keagenan dapat mengakibatkan adanya sifat manajemen melaporkan laba secara oportunitis untuk memaksimumkan kepentingan pribadi. Jika hal ini terjadi akan mengakibatkan rendahnya kualitas laba. Rendahnya kualitas laba akan dapat membuat kesalahan pembuatan keputusan kepada para pemakainya seperti para investor dan kreditor, sehingga nilai perusahaan akan berkurang. Laba yang kurang berkualitas bisa terjadi karena dalam menjalankan bisnis perusahaan, manajemen bukan merupakan pemilik perusahaan (Siallagan, 2006)

Menurut teori keagenan untuk mengatasi masalah ketidakselarasan kepentingan salah satunya adalah pengelolaan perusahaan yang baik (good corporate governance) (Anggraeni Niken Susanti, 2004-2007) Berdasarkan latar belakang dari penelitian diatas, maka penulis merumuskan beberapa kajian permasalahan yang akan diteliti mengenai good corporate governance dan kualitas laba, adalah 1) Bagaimana Good Corporate Governance (GCG) dan kualitas laba pada perusahaan real estate dan property yang terdaftar di Bursa Efek Indonesia (BEI) periode 2012-2017? 2) Bagaimana pengaruh Good Corporate Governance (GCG) terhadap kualitas laba (earnings quality) pada perusahaan real estate dan property yang terdaftar di Bursa Efek Indonesia (BEI) periode 2012-2017? Dan peneltian ini bertujuan untuk menganalisis Good Corporate Governance (GCG) dan Kualitas laba (earnings quality) pada perusahaan real estate dan property yang terdaftar di Bursa Efek Indonesia (BEI) dan menganalisis pengaruh Good Corporate Governance (GCG) terhadap kualitas laba (earnings quality) pada perusahaan real estate and property yang terdaftar di Bursa Efek Indonesia (BEI).

\section{KERANGKA TEORITIS DAN HIPOTESIS}

\section{Teori Keagenan (Agency Theory)}

Dalam perekonomian modern, manajemen dan pengelolaan perusahaan semakin banyak dipisahkan dari kepemilikan perusahaan. Hal ini sejalan dengan Agency Theory yang menekankan pentingnya pemilik perusahaan (pemegang saham) menyerahkan pengelolaan perusahaan kepada tenaga-tenaga professional (disebut agents) yang lebih mengerti dalam menjalankan bisnis sehari-hari (Sutedi, 2011)

Para tenaga-tenaga professional bertugas untuk kepentingan perusahaan dan memiliki keleluasaan dalam menjalankan manajemen perusahaan, sehingga dalam hal ini para professional tersebut berperan sebagai agent-nya pemegang saham. Semakin besar perusahaan yang dikelola memperoleh laba semakin besar pula keuntungan yang didapatkan agent. Sementara pemilik perusahaan (pemegang saham) hanya bertugas mengawasi dan memonitor jalannya perusahaan yang dikelola oleh manajemen untuk memastikan bahwa mereka bekerja demi kepentingan perusahaan (Sulistyanto, 2008)

Manajer sebagai pengelola perusahaan lebih banyak mengetahui informasi internal dan prosperk perusahaan di masa yang akan datang dibandingkan pemilik (pemegang saham). Manajer berkewajiban memberikan sinyal mengenai perusahaan kepada pemilik. Sinyal yang diberikan dapat dilakukan melalui pengungkapan inforamasi akuntansi seperti laporan 
keuangan. Ketidak seimbangan penguasaan informasi akan memicu munculnya suatu kondisi yang disebut sebagai informasi asimetri (information asymmetry) (Ujiantho dan Pramuka, 2007). Asimetri informasi adalah suatu kondisi di mana ada ketidakseimbangan perolehan informasi antara pihak manajemen sebagai penyedia informasi (prepaper) dengan pihak pemegang saham dan stakeholder pada umumnya sebagai pengguna informasi (user).

\section{Good Corporate Governance (GCG)}

Secara definitif good corporate governance diartikan sebagai sistem yang mengatur dan mengendalikan perusahaan agar perusahaan itu menciptakan nilai tambah (value added) untuk semua stakeholdersnya (Sulistyanto, 2008)

Forum for Corporate Governance in Indonesia ((FCGI), 2001) mendefinisikan GCG sebagai seperangkat peraturan yang mengatur hubungan antara pemegang, pengurus (pengelola) perusahaan, pihak kreditur, pemerintah, karyawan, serta para pemegang kepentingan internal dan eksternal lainnya yang berkaitan dengan hak-hak dan kewajiban mereka atau dengan kata lain suatu sistem yang mengendalikan perusahaan. Tujuan corporate governance ialah untuk menciptakan nilai tambah bagi semua pihak yang berkepentingan (stakeholders).

\section{Kualitas Laba}

Menurut (Chandarin, 2003) laba akuntansi yang berkualitas adalah laba akuntansi yang memiliki sedikit atau tidak mengandung gangguan persepsian (perceived noise), dan dapat mencerminkan kinerja keuangan perusahaan yang sesungguhnya. (Siallagan, 2006) menyatakan bahwa laba dikatakan berkualitas tinggi apabila laba yang dilaporkan dapat dipergunakan oleh para pengguna (users) untuk membuat keputusan yang terbaik, dan dapat digunakan untuk menjelaskan atau memprediksi harga dan return saham.

\section{PENGARUH GOOD CORPORATE GOVERNANCE TERHADAP KUALITAS LABA}

Pada dasarnya setiap orang mempunyai perilaku yang mementingkan diri sendiri atau self-interested behavior yang memberikan kecenderungan pihak manajer melakukan manipulasi kinerja perusahaan yang dilaporkan untuk kepentingannya sendiri (Boediono, 2005). (Boediono, 2005) masalah keagenan atau agency problem tejadi karena adanya perbedaan kepentingan antara pemegang saham dan manajemen yang masing-masing berusaha untuk memaksimumkan utilitasnya. Sesuai dengan teori keagenan, manajemen akan memilih metode tertentu untuk mendapatkan laba yang sesuai dengan motivasinya. Hal ini akan mempengaruhi kualitas laba yang dilaporkan, karena laba tidak mencerminkan kinerja ekonomi yang sesungguhnya. Rendahnya kualitas laba akan dapat membuat kesalahan pembuatan keputusan kepada para pemakainya seperti para investor dan kreditor, sehingga nilai perusahaan akan berkurang. Earnings dapat dikatakan berkualitas tinggi apabila earnings yang dilaporkan dapat digunakan oleh para pengguna (users) untuk membuat keputusan yang terbaik, dan dapat digunakan untuk menjelaskan atau memprediksi harga atau return saham (Siallagan, 2006)

Menurut teori keagenan untuk mengatasi masalah ketidaklarasan kepentingan salah satunya adalah pengelolaan perusahaan yang baik good corporate governance (GCG) (Anggraeni Niken Susanti, 2004-2007). Dengan meningkatkan Good Corporate Governance (GCG) diharapkan mampu meningkatkan kualitas laba dari perusahaan. Sehingga dengan 
kualitas yang baik diharapkan mampu memaksimalkan kinerja perusahaan yang berarti memaksimalkan return perusahaan (Istianingsih, 2012) Dalam penelitian ini, indikator untuk Good Corporate Governance (GCG) menggunakan Indeks Pengungkapan Corporate Governance (IPCG) yang menilai implementasi corporate governance suatu perusahaan berdasarkan pada pengungkapan prinsip-prinsip corporate governance dalam laporan tahunan perusahaan. IPCG ini dilengkapi dengan pengukuran yang digunakan peneliti-peneliti sebelumnya, berbagai literatur yang mendukung dengan memasukkan semua unsur yang terdapat dalam mekanisme corporate governance (Surifah, 2009) Dari kerangka pemikiran ini maka dikembangkan hipotesis yang diajukan dalam penelitian ini adalah :

$\mathrm{H}_{1}$ : Good Corporate Governance $(G C G)$ berpengaruh signifikan terhadap kualitas laba.

\section{Populasi dan Sampel}

\section{METODE PENELITIAN}

Populasi yang digunakan dalam penelitian ini adalah perusahaan real estate dan property yang listing di Bursa Efek Indonesia. Penelitian ini menggunakan teknik pengambilan sampel Non Probability Sampling yaitu teknik Purposive Sampling.

\section{Statistik Deskriptif}

Statistik deskriptif yang digunakan antara lain jumlah sampel (N), minimum, maksimum, rata-rata (mean) dan standar deviasi. Data variabel penelitian meliputi variabel dependen yaitu kualitas laba dan variabel independen yaitu Good Corporate Governance (GCG).

\section{Analisis Regresi Linear Sederhana}

Pada penelitian ini teknik analisis data yang digunakan adalah teknik analisis regresi sederhana untuk mengolah dan membahas data dalam menguji hipotesis yang diajukan. Analisis regresi sederhana didasarkan pada hubungan fungsional ataupun kausal satu variabel independen dengan satu variabel dependen (Sugiyono, 2011)

Persamaan umum regresi linear sederhana adalah:

Keterangan :

$$
\text { KUALITAS LABA }=\propto+\beta \text { GCG }+\varepsilon
$$

$\mathrm{KL} \quad=$ Kualitas laba

GCG = Good Corporate Governance (GCG)

$\propto \quad=$ Harga $\mathrm{Y}$ bila $\mathrm{X}=0$ (harga konstan)

$\mathrm{B}=$ Angka arah koefisien regresi, yang menunjukkan angka peningkatan ataupun penurunan variabel dependen yang didasarkan pada variabel independent. Bila $\beta(+)$ maka naik, dan bila $\beta(-)$ maka terjadi penurunan.

\section{Uji Asumsi Klasik}

Penelitian yang menggunakan model regresi sederhana harus memenuhi pengujian uji asumsi klasik. Uji asumsi klasik dilakukan untuk menentukan ketepatan model agar hasil penelitian tidak bias. Uji asumsi klasik yang digunakan dalam penelitian ini adalah uji normalitas, uji autokorelasi, dan uji heteroskedastisitas. 


\section{HASIL DAN PEMBAHASAN}

\section{Statistik Deskriptif}

Indeks Pengungkapan Corporate Governance (IPCG) adalah indeks yang menilai impelementasi corporate governance suatu perusahaan berdasarkan pada pengungkapan prinsip-prinsip corporate governance dalam laporan tahunan perusahaan yang dibangun berdasarkan pada asas-asas good corporate governance (GCG) menurut ((KNKG), 2006) dan juga dilengkapi dengan pengukuran dari penelitian-penelitian sebelumnya dan literatur yang mendukung dengan memasukkan semua unsur-unsur yang terkandung dalam mekanisme corporate governance (Surifah, 2009) Pada penelitian ini item tentang Corporate Social Responsibility (CSR) dan perolehan tentang peringkat kinerja lingkungan (PROPER) di dalam perusahaan dikeluarkan dari penelitian dikarenakan adanya keterbatasan penelitian. Dalam hal pengungkapan good corporate governance ini, peneliti mencoba membagi ke dalam 3 aspek yaitu: aspek operasional, aspek keuangan dan aspek kinerja mekanisme good corporate governance.

Hasil perhitungan Indeks Pengungkapan Corporate Governance (IPCG) dapat dilihat pada tabel 5.1 berikut :

Tabel 1

Indeks Pengungkapan Corporate Governance

\begin{tabular}{|c|c|c|c|c|c|c|c|c|}
\hline \multirow[t]{2}{*}{ No. } & \multirow{2}{*}{$\begin{array}{l}\text { Perusah } \\
\text { aan }\end{array}$} & \multirow[b]{2}{*}{2012} & \multicolumn{6}{|c|}{ Persentase Indeks Pengungkapan Corporate Governance } \\
\hline & & & 2013 & 2014 & 2015 & 2016 & 2017 & $\begin{array}{c}\text { Rata-rata/ } \\
\text { perusahaan }\end{array}$ \\
\hline 1. & APLN & 0,7165 & 0,7165 & 0,7165 & 0,7165 & 0,7165 & 0,7570 & 0,7134 \\
\hline 2. & ASRI & 0,6324 & 0,6324 & 0,6324 & 0,6324 & 0,6324 & 0,6355 & 0,6324 \\
\hline 3. & BAPA & 0,4953 & 0,4953 & 0,4953 & 0,4953 & 0,4953 & 0,5140 & 0,4953 \\
\hline 4. & BCIP & 0,5374 & 0,5374 & 0,5374 & 0,5374 & 0,5374 & 0,5514 & 0,5374 \\
\hline 5. & BKSL & 0,5374 & 0,5374 & 0,5374 & 0,5374 & 0,5374 & 0,5047 & 0,5374 \\
\hline 6. & COWL & 0,5530 & 0,5530 & 0,5530 & 0,5530 & 0,5530 & 0,5888 & 0,5530 \\
\hline 7. & CTRA & 0,6277 & 0,6277 & 0,6277 & 0,6277 & 0,6277 & 0,6168 & 0,6277 \\
\hline 8. & DILD & 0,6153 & 0,6153 & 0,6153 & 0,6153 & 0,6153 & 0,6449 & 0,6153 \\
\hline 9. & DUTI & 0,5545 & 0,5545 & 0,5545 & 0,5545 & 0,5545 & 0,6075 & 0,5545 \\
\hline 10. & ELTY & 0,6760 & 0,6760 & 0,6760 & 0,6760 & 0,6760 & 0,6636 & 0,7212 \\
\hline 11. & JRPT & 0,6199 & 0,6199 & 0,6199 & 0,6199 & 0,6199 & 0,6729 & 0,6199 \\
\hline 12 & KIJA & 0,5872 & 0,5872 & 0,5872 & 0,5872 & 0,5872 & 0,6262 & 0,5872 \\
\hline 13 & LPCK & 0,6246 & 0,6246 & 0,6246 & 0,6246 & 0,6246 & 0,6636 & 0,6246 \\
\hline 14 & LPKR & 0,6698 & 0,6698 & 0,6698 & 0,6698 & 0,6698 & 0,6729 & 0,6698 \\
\hline 15 & PWON & 0,6184 & 0,6184 & 0,6184 & 0,6184 & 0,6184 & 0,6449 & 0,6184 \\
\hline 16 & SCBD & 0,5514 & 0,5514 & 0,5514 & 0,5514 & 0,5514 & 0,5981 & 0,5514 \\
\hline 17 & SMRA & 0,5966 & 0,5966 & 0,5966 & 0,5966 & 0,5966 & 0,6355 & 0,5966 \\
\hline \multicolumn{2}{|c|}{ Mean/Th } & 0,57119 & 0,57779 & 0,59373 & 0,62067 & 0,61682 & 0,62342 & 0,57119 \\
\hline \multicolumn{2}{|c|}{ Minimum } & \multicolumn{7}{|l|}{0,4766} \\
\hline \multicolumn{2}{|c|}{ Maximum } & \multicolumn{7}{|l|}{0,7570} \\
\hline \multicolumn{2}{|c|}{ Standar deviasi } & \multicolumn{7}{|c|}{0,063708675} \\
\hline
\end{tabular}

Sumber: Data sekunder yang diolah tahun 2018

Tabel 1 menunjukkan persentase indeks pengungkapan corporate governance pada perusahaan real estate dan property tahun 2012-2017. Persentase indeks pengungkapan didapatkan dari jumlah nilai setiap pengungkapan perusahaan dibagi dengan total dari jumlah keseluruhan indeks pengungkapan yaitu 107 point. Dari data keseluruhan sampel, perusahaan 
yang mendapatkan nilai terendah adalah PT. Danayasa Arthatama Tbk, Tbk (SCBD) dengan nilai persentase 0.4766 pada tahun 2012.

Nilai rata-rata dari seluruh data sampel perusahaan dari tahun 2012-2017. adalah sebesar 0,60012 dengan 8 perusahaan mempunyai nilai di bawah rata-rata dan 9 Perusahaan dengan nilai di atas rata-rata. Nilai standar deviasi indeks pengungkapan good corporate governance adalah sebesar 0,062358 lebih kecil dari mean yaitu 0,60012 yang berarti data berkelompok, tidak terlalu bervariasi atau data cenderung menyebar di sekitar rata-rata.

Persentase indeks pengungkapan corporate governance setiap tahunnya meningkat dapat dilihat dari nilai rata-rata keseluruhan perusahaan pada tahun 2012 sampai dengan 2017. Walaupun meningkat setiap tahunnya, masih banyak perusahaan berada di bawah rata-rata. Namun demikian, perusahaan-perusahaan dengan nilai indeks pengungkapan corporate governance di bawah rata-rata pada tahun 2012-2017. juga termasuk pada perusahaan yang kategorisasi pemeringkatan Corporate Governanace Perception Index (CGPI) dengan predikat cukup terpercaya dengan Skor 55-69.

\section{Kualitas Laba}

Pengukuran kualitas laba pada penelitian ini dengan menggunakan prediktabiltas laba. Prediktabilitas laba merupakan laba yang dapat digunakan sebagai dalam memprediksi laba di masa datang. Laba yang berkualitas tinggi adalah laba yang mempunyai kemampuan yang tinggi dalam memprediksi laba di masa datang (Sutopo, 2009) Hasil perhitungan kualitas laba dapat dilihat pada tabel 5.2 berikut:

Tabel 2

Kualitas laba

\begin{tabular}{|c|c|c|}
\hline \multirow[t]{2}{*}{ No. } & \multirow[t]{2}{*}{ Perusahaan } & \multirow{2}{*}{$\begin{array}{c}\text { Prediktabilitas Laba } \\
\sqrt{\sigma}^{2}\left(v_{j}\right)\end{array}$} \\
\hline & & \\
\hline 1 & APLN & 2,8030 \\
\hline 2 & ASRI & 6,4580 \\
\hline 3 & BAPA & 3,0074 \\
\hline 4 & BCIP & 5,8688 \\
\hline 5 & BKSL & 2,8749 \\
\hline 6 & COWL & 4,7723 \\
\hline 7 & CTRA & 12,2549 \\
\hline 8 & DILD & 3,8127 \\
\hline 9 & DUTI & 9,8652 \\
\hline 10 & ELTY & 4,5698 \\
\hline 11 & JRPT & 7,2425 \\
\hline 12 & KIJA & 2,5839 \\
\hline 13 & LPCK & 170,3619 \\
\hline 14 & LPKR & 12,9382 \\
\hline 15 & PWON & 163,0686 \\
\hline 16 & SCBD & 74,7094 \\
\hline 17 & SMRA & 9,0470 \\
\hline 18 & APLN & 2,8030 \\
\hline \multicolumn{2}{|c|}{ Minimum } & 2,5839 \\
\hline \multicolumn{2}{|c|}{ Maximum } & 170,3619 \\
\hline \multicolumn{2}{|c|}{ Mean } & 29,1905 \\
\hline \multicolumn{2}{|c|}{ Standar deviasi } & 54,44375937 \\
\hline
\end{tabular}

Prediktibilitas laba ini diukur dari standar deviasi error hasil regresi antara net income before extraordinary $\left(\mathrm{NIBE}_{\mathrm{t}}\right)$ yang dibagi dengan rata-rata jumlah saham beredar tahun 
sekarang $(\mathrm{t})$ dan net income before extraordinary $\left(\mathrm{NIBE}_{\mathrm{t}-1}\right)$ yang dibagi dengan rata-rata jumlah saham beredar tahun sebelumnya $(\mathrm{t}-1)$. Dengan asumsi bahwa laba semakin prediktibilitas apabila regresi menghasilkan standar deviasi error yang kecil. Dengan demikian semakin besar (kecil) standar deviasi menunjukkan kualitas laba yang semakin rendah (tinggi) (Francis, Lafond, Olsson, \& Schipper, 2004)

Tabel 2 dapat dilihat bahwa perusahaan yang memilki nilai standar deviasi error tertinggi yang dapat disimpulkan mempunyai kualitas laba terendah adalah PT. Lippo Cikarang Tbk (LPCK) dengan nilai prediktabilitas sebesar 170,3619, perusahaan ini mempunyai nilai standar deviasi error yang besar, hal ini mengindikasikan bahwa perusahan ini mempunyai kualitas laba yang rendah. Kualitas laba yang rendah ini menunjukkan bahwa laba mempunyai kemampuan yang rendah dalam memprediksikan laba yang akan datang.

Perusahaan yang memiliki nilai standar deviasi error yang terendah yang mengindikasikan mempunyai kualitas laba yang tertinggi diperoleh PT. Kawasan Industri Jababeka Tbk (KIJA) dengan nilai prediktabilitas sebesar 2,5839. perusahaan ini mempunyai nilai standar deviasi error yang kecil, hal ini mengindikasikan bahwa perusahan ini mempunyai kualitas laba yang tinggi. Kualitas laba yang tinggi ini menunjukkan bahwa laba mempunyai kemampuan yang tingi dalam memprediksikan laba yang akan datang. Hal ini disebabkan karena laba yang diperoleh perusahaan ini mengalami peningkatan atau penurunan yang relatif tidak signifikan pada setiap tahunnya.

Rata-rata nilai prediktabilitas laba adalah sebesar 29,1905. Dengan 4 perusahaan yang mempunyai nilai di atas rata-rata dan 13 perusahaan yang mempunyai nilai di bawah rata-rata. 13 perusahaan yang mempunyai nilai di bawah rata-rata menunjukkan nilai prediktabilitas laba yang tinggi dengan hasil standar deviasi dari error yang kecil sehingga mengindikasikan kualitas laba yang baik. Dan sebaliknya 4 perusahaan yang mempunyai nilai di atas rata-rata menunjukkan laba yang kurang prediktabilitas dengan hasil standar deviasi dari error yang besar sehingga mengindikasikan kualitas laba yang kurang baik.

\section{Uji Asumsi Klasik}

Penelitian yang menggunakan model regresi sederhana harus memenuhi pengujian uji asumsi klasik. Uji asumsi klasik dilakukan untuk menentukan ketepatan model agar hasil penelitian tidak bias. Uji asumsi klasik yang digunakan dalam penelitian ini adalah sebagai berikut:

\section{Hasil Uji Asumsi Klasik}

\begin{tabular}{l|c|c|c}
\hline \multicolumn{1}{c|}{ Variabel } & Hasil & Persyaratan & Keterangan \\
\hline Normalitas & 0,07 & Sig $>0,05$ & Distribusi Normal \\
\hline Multikolinearitas & Toleransi $>0,1$ dan VIF & Toleransi $>0,1$ dan VIF & Bebas \\
& $<10$ & $<10$ & Multikolinearitas \\
\hline Heteroskedastisitas & 0,$054 ; 0.512 ; 0,280 ;$ & Sig $>0,05$ & Bebas \\
& 0,429 & & Heteroskedastisitas \\
\hline
\end{tabular}

Sumber : Data primer diolah, 2017

\section{Koefisien Determinasi (R Square)}

Koefisien determinasi $\left(\mathrm{R}^{2}\right)$ pada intinya mengukur seberapa jauh kemampuan model dalam menerangkan variasi variabel dependen. Nilai $R^{2}$ yang kecil berarti kemampuan variabel independen dalam menjelaskan variasi variabel dependen amat terbatas (Ghozali, 2011). Berikut ini adalah hasil perhitungan koefisien determinasi: 
PENGARUH GOOD CORPORATE GOVERNANCE...

Vika Fitranita dan Isma Coryanata

Tabel 4

Koefisien Determinasi

\begin{tabular}{l|c|c|c|c|r}
\hline \multicolumn{6}{c}{ Model Summary $^{\mathbf{b}}$} \\
\hline Mode & $\mathrm{R}$ & $\begin{array}{c}\mathrm{R} \\
\text { Square }\end{array}$ & $\begin{array}{c}\text { Adjusted R } \\
\text { Square }\end{array}$ & $\begin{array}{c}\text { Std. Error of } \\
\text { the Estimate }\end{array}$ & $\begin{array}{c}\text { Durbin- } \\
\text { Watson }\end{array}$ \\
\hline 1 & $.080^{\mathrm{a}}$ & .006 & -.060 & 560501.5905 & 1.891 \\
\hline
\end{tabular}

a. Predictors: (Constant), GCG

b. Dependent Variable: KUALITAS LABA

Sumber: Data sekunder yang diolah tahun 2018

Tabel 4.4 di atas memperlihatkan nilai $\mathrm{R}^{2}$ ( $R$ square) sebesar $0,6 \%$. Hal ini menunjukkan bahwa kemampuan variabel independen yaitu Good Corporate Governance (GCG) dalam menjelaskan variasi variabel dependen yaitu kualitas laba adalah sebesar 0,6\% sedangkan sisanya sebesar dijelaskan oleh variabel lain di luar model penelitian.

\section{Pengujian Hipotesis}

Pengujian hipotesis pada dasarnya digunakan untuk mengetahui pengaruh variabel independen yaitu good corporate governance terhadap variabel dependen yaitu kualitas laba. Untuk menginterpretasikan koefisien variabel independen (bebas) dapat menggunakan hasil analisis regresi seperti tersaji pada table 4.5 di bawah ini:

\section{Tabel 4.5}

\section{Uji Signifikansi Secara Parsial (Uji t)} Coefficients $^{\mathrm{a}}$

\begin{tabular}{l|l|l|l|l|l|l}
\hline \multicolumn{2}{l|}{ Model } & \multicolumn{2}{l|}{ Unstandardized Coefficients } & $\begin{array}{l}\text { Standardized } \\
\text { Coefficients }\end{array}$ & \multirow{2}{*}{ Sig. } \\
\cline { 3 - 5 } \multicolumn{2}{c|}{} & $\mathrm{B}$ & Std. Error & Beta & \\
\hline \multirow{2}{*}{1} & (Constant) & -16335.035 & 147537.546 & & -.111 & .913 \\
\cline { 2 - 6 } & GCG & 7.580 & 24.460 & .080 & .310 & .761 \\
\hline
\end{tabular}

a. Dependent Variable: KUALITAS LABA

Sumber: Output SPSS, Coefficients

Variabel dependen pada model regresi ini adalah kualitas laba sedangkan variabel independen adalah Good Corporate Governance (GCG). Model regresi berdasarkan hasil analisis tabel adalah:

\section{KUALITAS LABA $=-\mathbf{- 1 6 . 3 3 5 , 0 3 5}+7.580$ GCG $+\varepsilon$}

Penjelasan dari persamaan diatas adalah sebagai berikut:

Nilai konstanta sebesar -16.335,035 menunjukkan variabel independen yaitu Good Corporate Governance (GCG) bernilai nol maka besaran kualitas laba adalah sebesar 16.335,035. Koefisien regresi Good Corporate Governance (GCG) sebesar 7.580 menyatakan bahwa setiap penambahan 1 Good Corporate Governance (GCG), maka kualitas laba akan meningkat sebesar 7.580, hal tersebut mengindikasikan bahwa apabila perusahaan melakukan Good Corporate Governance (GCG) dapat meningkatkan kualitas laba sebesar 7.580. Pada tabel 4.5 Terlihat bahwa tingkat signifikan 0,761 dimana nilai ini lebih besar dari $\alpha=0,05$. Dengan demikian $\mathrm{H}_{\mathrm{a}}$ ditolak dan $\mathrm{H}_{\mathrm{o}}$ diterima artinya Good Corporate Governance $(G C G)$ tidak berpengaruh signifikan terhadap kualitas laba.

Nilai koefesien regresi untuk Good Coproate Governance (GCG) sebesar 7.580 menunjukkan bahwa Good Corporate Governance (GCG) mempunyai arah koefisien yang positif terhadap kualitas laba, yang berarti bahwa semakin besar Good Corporate Governance (GCG) maka akan meningkatkan kualitas laba. Hal ini dapat didukung hasil pengungkapan Good Corporate Governance (GCG) yaitu pada aspek operasional, aspek keuangan dan aspek 
kinerja dan mekanisme Good Corporate Governance (GCG) yang mengalami peningkatan dari tahun ke tahun selama periode penelitian, yang dapat disimpulkan bahwa dari tahun ke tahun pengungkapan Good Corporate Governance (GCG) yang diungkapkan di laporan keuangan tahunan perusahaan semakin baik. Dengan pengungkapan Good Corporate Governance (GCG) yang semakin baik, penerapan Good Corporate Governance (GCG) didalam perusahaan juga baik. Prediktabilitas laba perusahaan didapatkan dari 5 tahun periode penelitian. Dalam 5 tahun periode penelitian tersebut perusahaan dapat memprediksikan laba masa yang akan datang. Dari hasil penelitian, dapat disimpulkan bahwa semakin baik pengungkapan tentang Good Corporate Governance (GCG) yang disertai oleh penerapan dan pelaksanaan Good Corporate Governance (GCG) di dalam perusahaan, maka akan meningkatkan kualitas laba.

\section{PENUTUP}

\section{Simpulan}

Berdasarkan hasil pengujian dan analisis menggunakan metode analisis statistik deskriptif, uji asumsi klasik, analisis regresi linear sederhana dan pengujian hipotesis, diperoleh beberapa kesimpulan yaitu dari 17 perusahaan yang menjadi sampel perusahaan terdapat 8 perusahaan yang mempunyai nilai persentase indeks corporate governance di bawah rata-rata dan 9 perusahaan mempunyai nilai di atas rata-rata. Dengan setiap tahun indeks pengungkapan corporate governance mengalami peningkatan yang mengindikasikan perusahaan semakin melaksanakan pelaksanaan tata kelola perusahaan dengan baik dan telah mengungkapkan tentang good corporate governance di dalam laporan keuangan tahunan perusahaan.

Pada variabel kualitas laba terdapat 4 perusahaan yang berada di atas nilai rata-rata dan 13 perusahaan dengan nilai di bawah rata-rata. 4 perusahaan tersebut dapat diindikasikan mempunyai laba yang kurang prediktabilitas sehingga kualitas laba perusahaannya rendah, sedangkan 13 perusahaan yang mempunyai nilai di bawah rata-rata dapat diindikasikan bahwa perusahaan tersebut memiliki laba yang prediktabilitas, sehingga dapat disimpulkan bahwa perusahaan memiliki kualitas laba yang baik. Hasil uji secara parsial (uji t) pengaruh Good Corporate Governance terhadap kualitas laba pada perusahaan real estate dan property 20122017 yaitu signifikansi Good Corporate Governance sebesar 0,018 dimana nilai ini lebih kecil dari $\alpha=5 \%$. Hal ini menunjukkan bahwa variabel Good Corporate Governance berpengaruh signifikan terhadap kualitas laba.

\section{Saran}

Berdasarkan hasil penelitian, pembahasan dan kesimpulan diatas serta pertimbangan masih adanya keterbatasan dalam penelitian ini, maka penelitian selanjutnya dapat mempertimbangkan saran-saran berikut :

1. Menggunakan proksi lain untuk mengukur Good Corporate Governance seperti dengan menggunakan Corporate Governance Perception Index, atau indeks Corporate Governance yang berasal dari Indonesian Institute for corporate directorship (IICD).

2. Menggunakan objek penelitian yang berbeda dari jenis industri lainnya atau menambah populasi perusahaan dari semua industri yang terdaftar di Bursa Efek Indonesia (BEI).

3. Menambah periode tahun pengamatan atau menggunakan rentang waktu pengamatan yang berbeda, karena apabila hanya menggunakan 2 tahun periode pengamatan yang diamati, hasilnya tidak dapat menunjukkan kepastian laba di masa yang akan datang. Sehingga disarankan bagi peneliti selanjutnya untuk menggunakan periode pengamatan 4 tahun atau lebih, dengan lamanya periode -tahun yang diamati mampu mewakili perusahaanperusahaan yang mempunyai laba yang prediktabilitas atau sebaliknya. 
PENGARUH GOOD CORPORATE GOVERNANCE...

Vika Fitranita dan Isma Coryanata

\section{DAFTAR PUSTAKA}

(FCGI), F. f. (2001).

(KNKG), K. N. (2006). Pedoman Umum Good Coprorate Governance.

Anggraeni Niken Susanti, R. d. (2004-2007). Analisi Pengaruh Mekanisme Corporate Governance Terhadap Nilai Perusahaan Dengan Kualitas Laba sevagai ariabel Intervening pada Perusahaan Manufaktur yang terdaftar di Bursa Efek Indonesia.

Boediono, G. (2005). Kualitas Laba : Studi Pengaruh Mekanisme Corporate Governance dan Dampak Manajemen Laba denga Menggunakan Analisis Jalur. Simposium Nasional Akuntansi VIII, Solo.

Chandarin, G. (2003). The impact for transaction Gain (losess) on The Earning Response Coefficient. The Indonesian Case. Jurnal Riset Akuntansi, Indonesia, Vol 6, No. 3.

Francis, J., Lafond, R., Olsson, P., \& Schipper, a. K. (2004). Cost of Equity and Earning Attributes. The Accounting Review, Vol, 79 No. 4,Oktober.

Ghozali, I. (2011). Aplikasi Analisis Multivariate dengan Program IBM SPSS 19. Semarang: Badan Penerbit Universitas Dipenogoro.

Istianingsih, M. d. (2012). Pengaruh Good Coproate Governance Terhadap Kualitas Laba dan Dampaknya Pada Kinerja Perusahaan. Universitas Tarumanegara, jakarta.

Siallagan, H. d. (2006). Mekanisme Corporate Governance, Kualitas Laba dan Nilai Perusahaan. Simposum Nasional Akuntansi IX. IAI, Padang.

Sugiyono. (2011). Staatistika untuk Penelitian. Bandung: Alfabeta.

Sulistyanto, S. (2008). Manajemen Laba; Teori dan MoelImpiris, Jakarta. Pt. Gramedia Widiasarana Indonesia.

Surifah. (2009). Arranging The Index of Corporate Governance. Dinamika Manajemen, Vol. 13 No. 1 Maret 2011.

Sutedi, A. (2011). Good Corporate Governance. Sinar Grafika.

Sutopo, B. (2009). Manajemen Laba dan Manfaat Kualitas dalam Keputusan Investasi. Universitas Sebelas Maret.

Triatmoko, R. A. (2007). Analisis Faktor-faktor yang mempengaruhi Kualitas Laba dan Nilai Perusahaan. Simposium Nasional Akuntansi X, Makassar.

Utari, W. A. (2006). Analisis Faktor-Faktor Yang Berpengaruh Terhadap Earnings Management pada Perusahaan Go Public Di Indonesia. Simposium Nasional Akuntansi 9, Padang. 